\title{
Why Is Governance Research Important for University Reforms in Ukraine?
}

\author{
Anatoly V. Oleksiyenko \\ Ph.D., Associate Professor, University of Hong Kong (Hong Kong, China) \\ E-mail:paoleks@hku.hk \\ https://orcid.org/0000-0002-1035-9186
}

\begin{abstract}
One of the obvious drawbacks to academic reforms in Ukraine has been the lack of systematic research on governance practices and challenges in higher education. The deficiency of empirical data on governance processes is unsurprising in the context of Soviet legacy. Indeed, many Soviet-style universities lack the tradition and experience of doing research on themselves for either internal use or for public reporting. Post-totalitarian academic communities are particularly vulnerable when faculty members are afraid to share their views and opinions, especially regarding the holders of senior positions on whom their tenure depends. The article is an attempt to answer the following questions: What can be done to change the organizational culture in post-Soviet universities and steer it toward self-reflection and critical inquiry? What kind of policy research may be needed to change the university governance from an authoritarian model that advocates for selection of personnel on the basis of loyalty, to a selfregulated system that promotes and celebrates academic merit?
\end{abstract}

Keywords: post-totalitarian academic community, Ukrainian postcolonial university, university reform, governance research, educational governance, higher education policy, Soviet legacy

Received: April 12, 2019; accepted: May 16, 2019

Ukrainian Policymaker, Volume 4, 2019: 27-35.

https://doi.org/10.29202/up/4/5

\section{Introduction}

One of the obvious drawbacks to academic reforms in Ukraine has been the lack of systematic research on governance practices and challenges in higher education. The deficiency of empirical data on governance processes is unsurprising in the context of Soviet legacy. Indeed, many Soviet-style universities lack the tradition and experience of doing research on themselves for either internal use or for public reporting. Post-totalitarian academic communities are particularly vulnerable when faculty members are afraid to share their views and opinions, especially regarding the holders of senior positions on whom their job contracts depend. Studies in higher education are absent as a subject of post-graduate education and scholarship, and institutional research is not seen as crucial for improvement of university management and

(C) Oleksiyenko, Anatoly, 2019 
policy making. Very few researchers have the necessary courage and knowledge to attempt in-depth critical analysis of their own universities, authorities or practices. Meanwhile, the tokenism of grassroots consultations and the tradition of authoritarianism within institutions prolong a belief in the uselessness of data, and a sense disempowerment among faculty members and students. Instead, external and internal analysts tend to over-emphasize the role of top-down steerage in institutional transformations. In the absence of clear ideas about the status of existing governance challenges at universities, governmental regulators and institutional managers generally opt for "one size fits all" solutions.

What roles can institutional research play in developing quality research on university governance Can university managers develop a reporting system that discourages the postSoviet traditions of rigidity of compliance and fear of feedback? What can stimulate critical inquiry and continuous quality improvement of administrative procedures in universities? What types of management/governance performance criteria are necessary for monitoring progress in transitional contexts, where competitive skills and enhanced productivity are needed, but where mistrust of management and concerns about entitlements proliferate?

In the following sections, I will outline key directions for change, and I will draw on reflections from my experiences with governance research in Ukraine, as well as correlate those with the related work in Cambodia, Canada, China, Hong Kong, Kazakhstan and Russia. Some further findings from that research can be found in the listed papers below.

\section{From rigid institutional culture to critical inquiry}

It will be extremely difficult to achieve a turnaround in the post-Soviet university administration without managers who champion systematic institutional research, encourage critical inquiry in university governance, and support public reporting on higher education transformations. The current administrative system in Ukrainian universities primarily relies on topdown control of academics and students [Oleksiyenko, 2016]. Most managers have a vested interest in sustaining the illusion of control over human resources, despite the fact that mass higher education makes micro-management ineffective and requires that ultimate responsibility be devolved to the frontline of teaching, research, and service [Ian \& Jones, 2016; Paradeise et al., 2009]. In the higher education systems with the Soviet legacy (see more on the concept in [Kuraev, 2016]), top-down control of people and data has been a key administrative resource for decades (if not centuries) and it has been helpful in sustaining (or manipulating) organizational legitimacy and powers [Oleksiyenko, 2016; Oleksiyenko et al., 2018]. The alternative - i.e., reliance on the currency of data analysis - makes post-Soviet managers cringe, as it signifies loss of control over image and impression management in the so-called democratic (and arguably treacherous) political environment. Unflattering reports on declining student enrolment and university rankings make managers in many vulnerable higher education systems recoil from putting their trust in public inquiry and data-driven interpretations [Amaral et al., 2013; Vidovich \& Currie, 2011].

Indeed, very few post-Soviet managers take full advantage of institutional research [Chirikov, 2013; Hladchenko et al., 2017]. In Ukraine, flagship universities appear to do it for statistical purposes only [Oleksiyenko, 2014]. The statistical data reveal trends and illuminate the status of change across major indicators of performance: e.g., student enrolment, workload distribution, budgetary flows, etc. Meanwhile, valuable factors such as faculty and student expectations, and learning outcome parameters, are often overlooked in the absence of refined 
field-specific and program-specific data. The large-scale research is expensive, and has little value without longitudinal data-sets. Moreover, when the higher administrative echelons rely on impression management more than on tangible data, the rigor of research fails and the politics of reporting intensify.

Augmenting the value of institutional (plus governance) research is critical if the Ukrainian public wants to regain control over its public universities. Evidence-based critical inquiry is the only perspective that shapes the idea and value of public good [Amaral et al., 2009; Kohler \& Huber, 2006]. In the post-colonial discourse of the Ukrainian nation-state, such inquiry would provide greater insights into the power relations among faculty members, students, and administrators. Making the university power brokers (in particular rectors and their executive echelons) more accountable for the distribution and investment of resources would serve the growing demand for the public good to be owned by everyone in society, rather than just by the privileged few [see, Stensaker \& Vabø, 2019].

Simultaneously, managers of public institutions must become more professional in handling the complexity of access and excellence in higher education. Fear and resistance on their part is to be expected, given that most of them have not been prepared for data use and evidencebased management. The lack of proper education and information systems is at the root of the fears. In that regard, it is essential that research skills become a major criterion in recruiting and promoting university managers [Oleksiyenko, 2018; Padure \& Jones, 2009]. Data-oriented and research-competent managers should be properly recognized and rewarded. I would argue that these managers need to be publicly acknowledged for demonstrating excellence in data-driven management of institutional transformations. Moreover, they should be regarded as models of excellence in institutional (or governance) research when their use of data supersedes primitive statistics gathering and they develop appropriate grassroots feedback mechanisms.

The rewards should be introduced through a national forum conducted by the Ministry of Education and Science, and several civic organizations known for their credibility in higher education research (e.g., CEDOS). The award ceremonies will acquire more legitimacy and international resonance if they are preceded by a rigorous selection process involving internationally-acclaimed peer-reviewers. These reviewers should make their decisions on the basis of annual portfolios of institutional data and stories, which clearly demonstrate where and how transformative progress had been made, and how it contributes to improved performance, greater transparency and comprehensive public accountability of universities. These stories can be then widely shared (and even benchmarked) by the Ministry and the National Quality Assurance Agency to facilitate a cross-organizational learning process in the university system.

\section{Research supporting merit-oriented governance}

It is also important to stimulate several flagship universities (by encouraging competitiveness, as well as diversity in reporting) to develop policy think-tanks on university governance. Institutional commitment to sustained data collection and analysis using powerful tools is increasingly needed in a context where institutional governance used to be cultivated as a vehicle of self-service (meaning serving the local bureaucracy), rather than as an instrument for improved quality of research, teaching and learning [Hladchenko et al., 2016; Locke et al., 2011; Sagintayeva \& Kurakbayev, 2015].

An effective agency for governance research can evolve only at flagship universities with a strong academic culture of innovation-oriented interdisciplinary studies, organizational 
resilience, and ambition for intellectual leadership [Kezar \& Eckel, 2002; Tierney, 2014]. Meanwhile, across universities in Ukraine, entitlements and conveniences are shaped to sustain managers' and lecturers' positions regardless of the quality of their work and impact [Oleksiyenko, 2014]. If institutions of higher learning are permeated by the self-service philosophy, then their members are likely to be uninterested in challenging themselves with increased competition, external reviews, and innovative disruption. The Ukrainian Ministry of Education and Science would need to invest in those flagship centers that have salience of legitimacy, power, and urgency to advance governance research and discourse on academic excellence. This would help both academic and professional societies re-conceptualize the meanings of governance [Hladchenko, 2016], as well as find better ways to mitigate a conflict between meritocracy and mediocrity, which has been depreciating human and institutional capital in higher education over the last decade.

\section{Institutional research as a step to improved governance}

Institutional research can serve as an important step in developing a system-wide culture of analysis that could help university leaders understand the currency of student and stakeholder demands, structural transformations and capacities, as well as financial infrastructures for managing academic challenges and changes [Braskamp \& Ory, 1994; Chirikov, 2013]. However, institutional research works well only in ambitious systems, in which faculty and managers have a clear understanding of the value of knowledge about disparate stakeholder demands and financial flows [Altbach \& Salmi, 2013]. A solid grasp of these demands and expectations allows for better communication with sponsors. It also creates a clearer picture of where adjustments are needed to satisfy the most urgent interests and concerns, and to enable synergies and partnerships for more effective utilization of resources.

Institutional research becomes particularly valuable when competition for resources increases across institutions, and when the previously advantaged universities suddenly experience anxiety about organizational survival. The higher education system benefits when all peer institutions agree on openly sharing their progress in the organizational field, thus encouraging the survival of the whole field, rather than random institutions. In the absence of a trust-based agreement on fair competition in the organizational field (i.e., among peer institutions), institutional research has relatively low value. Unfortunately, the level of trust seems to be very low in the divided post-colonial environment of Ukrainian universities [Svyrydenko, 2017]. Trust has been further deteriorating under the managerially-controlled system which creates cushions for privileged managers, and sticks and stones for those who do not have exclusive access to the executive offices in the Ukrainian government [Oleksiyenko, 2016]. In the absence of open and fair competition, many privileged rectors feel that they can achieve more by relying on impression and relationship management. In view of the declining subsidies for higher education, they increasingly resist the introduction of competitive mechanisms. As a result, both system-level and institutional-level governance mechanisms suffer from corruption and mistrust. To mitigate this problem, transparent and easily-accessible institutional research becomes crucial.

\section{Making research significant for organizational change}

The value of governance research increases when universities seek opportunities to improve the quality of their institutional design, as well as to enhance the services that 
university stakeholders increasingly expect from academics [Jongbloed et al., 2008]. The complexity of the campus and its environmental conditions necessitates better insights into the logic and influence of university policies, structures, and organizational cultures [Bleiklie \& Kogan, 2007]. Influential world-class universities, such as the University of Toronto or the University of Hong Kong, have graduate programs at the master's and doctoral degree levels to train university administrators to conduct institutional research in particular, as well as academic research in general. The professionally-trained and research-aware administrators act very differently from their counterparts, who have limited knowledge and skills related to research. When it comes to shaping institutional policies and implementation mechanisms, the degree holders in higher education policy and administration ask much deeper questions, and their thinking is more critical than that of practitioners without this educational background. Most importantly, they have a much better understanding of multi-stakeholder environments characterized by competing values, ideas, and expectations. They also have the capability to effectively link research with policy and practice to empower a more research-driven and evidence-based organizational change.

The organizational climate flourishes when faculty members and administrators recognize that their universities are managed by thoughtful and critically-minded professionals. These professionals' attitudes and skills initially depend on the philosophies and cultural values imparted by professors in their graduate programs. Hence, administrative professionals from top-ranking universities tend to be recruited and promoted by ambitious systems and institutions of higher learning. Notwithstanding this initial advantage, their analytical capacities develop further only if they are engaged in regular and rigorous development of institutional data, which is reviewed by peers and users in policy-making and implementation. Cognizant of the problem of capacity deficiencies, competitive professionals engage in life-long learning and actively upgrade their methodological and conceptual skills in institutional research and higher education management.

\section{Research communication for greater faculty empowerment}

Governance issues should be a subject of general academic curiosity, concern, and engagement. Inclusive research communication allows the governance process to transcend the formality and exclusivity of discussions and decisions made within the structures and meetings of special executive committees, academic councils or senates, and faculty boards [Rowlands, 2013]. The literature of the last several decades shows that academic citizenship and a sense of institutional responsibility are critical for improving processes and outcomes in teaching and research [Oleksiyenko \& Ruan, 2019]. Professors and students tend to be more committed and impactful in their work when they are regarded as important contributors to academic development.

Open data and open discussions are extremely important in shaping an environment that empowers citizens and enables committed participation in institutional change. For data analysis and communication to be impactful, it is important that research results are presented and debated in regular forums, rather than discovered through serendipitous events and random perusal of web-sites and publications. The producers of data should be available and facilitative, rather than faceless and unresponsive.

Increased trust in research communication allows for higher quality input from institutional participants [Vidovich \& Currie, 2011]. Once they know that data work for them, rather than 
against them, they will seek opportunities for interaction and provide more valuable inputs. This is particularly true regarding qualitative data collection and analysis. In-depth and sincere feedback from various levels and degrees of responsibility across university units provides not only an essential supplement to statistical data, but also vital insights that drive the participation, sharing, and contributions needed to succeed to complete joint tasks and achieve university-wide targets [Vukasović \& Elken, 2013].

\section{Sensible criteria for monitoring the progress of openness}

Post-Soviet institutions suffer from the legacy of top-down suppression of criticism and dissent [Oleksiyenko, 2018]. The culture of inviting upstream criticism is rudimentary. As a result, neither are the grassroots proficient in communicating problems in an informed and constructive way, nor are their managers skillful in handling 'inconvenient' data inputs and critical feedback. To address this problem, both local and international reviewers involved in the earlier suggested award committees would need to engage assessment criteria that stimulate constructive, data-driven and evidence-based openness in the post-totalitarian institutions. Such criteria may include: numbers of survey participants at each governance level; quantity and quality of feedback to institutional surveys; number and quality of actions proposed and taken to implement institutional improvements as a result of survey findings; number and quality of publications shared in scholarly and professional journals at home and abroad; feedback received through social media; and development of department-based and center-based bulletins on handling stakeholder interests in research, teaching and knowledge transfer, etc.

The selection and substance of the criteria can be determined through stakeholder-engaging discussions at various levels of administration. Once the 'citizens' of academic departments and research centers agree on what makes sense to them when it comes to monitoring their environments and results, those criteria will gain more weight in the value systems of the stakeholders. The generated data can also provide more sophisticated inputs to institutional web-pages, social media, and special reports.

\section{Responsibility for greater integration with the EU and removal of the Soviet legacy}

Consideration of the dichotomy between the EU and the Soviet legacy university management becomes increasingly important in view of a greater push from the Ukrainian public to create a European-type of university and become more effective members of the European space of higher education. In response to public demands, Ukrainian institutional researchers need to seek greater integration of the EU criteria for development of good governance systems in academia [see, Amaral et al., 2009; Dobbins et al., 2011; Magalhães et al., 2013]. The Ukrainian Ministry of Education and Science has been making significant contributions to legislation supporting such integration. However, little work has been done at the institutional level in most universities. The process cannot gain momentum until EU integration offices emerge as strategic centers in universities and are endowed with responsibility to initiate, support and monitor program-level adjustments in accordance with EU standards. Such offices should be attached to the rector's office, in order to enable legitimization of data development, and to intensify institution-wide development of international linkages and collaborations that enhance Ukrainian researchers' engagement with European schemes of accountability. 


\section{Conclusions}

More discussion is needed on the development of appropriate research and information systems for good governance in post-totalitarian universities. Previous research suggests that significant achievements can be made in post-totalitarian systems when the three levels of governance: superstructure (governmental agencies), structure (university executive teams and faculties), and understructure (research centers and intellectual leaders across the disciplines) are properly aligned for enacting change [Oleksiyenko et al., 2018]. Regrettably, the Ukrainian system of higher education has been characterized by severe misalignments over the last few decades [Hladchenko et al., 2018].

It can be argued that these misalignments are driven by the willful and uncoordinated actions of forceful managers who are concerned about their private gain, rather than the public good. Undoubtedly, they have also been driven by a lack of suitably sophisticated information systems open for public review, debate, monitoring and benchmarking. Yet, this does not mean that multilevel governance alignments cannot be achieved.

\section{References}

Altbach, Philip G., and Jamil Salmi. (Eds.). The road to academic excellence: The making of world-class research universities. Washington, DC: The World Bank, 2011.

Amaral, Alberto, Glen A. Jones, and Berith Karseth. (Eds.). Governing higher education: National perspectives on institutional governance (Vol. 2). Springer Science \& Business Media, 2013.

Amaral, Alberto, Guy Neave, Christine Musselin, and Peter Maassen (Eds.). European integration and the governance of higher education and research (Higher Education Dynamics Book 26). Springer Netherlands, 2009.

Austin, Ian, and Glen A. Jones. Governance of higher education: Global Perspectives, Theories and Practices. New York and Oxon: Routledge, 2016.

Bleiklie, Ivar, and Maurice Kogan. Organization and governance of universities. Higher Education Policy, 20(4), 2007: 477-493. https://doi.org/ 10.1057/palgrave.hep.8300167

Braskamp, Larry A., and John C. Ory. Assessing Faculty Work: Enhancing Individual and Institutional Performance. San Francisco, CA: Jossey-Bass Higher and Adult Education Series, 1994.

Chirikov, Igor. Research universities as knowledge networks: the role of institutional research. Studies in Higher Education, 38(3), 2013: 456-469. https://doi.org/10.1080 /03075079.2013.773778

Dobbins, Michael, Christoph Knill, and Eva Maria Vögtle. An analytical framework for the cross-country comparison of higher education governance. Higher Education, 62(5), 2011: 665-683. https://doi.org/ 10.1007/s10734-011-9412-4

Hladchenko, Myroslava, Harry F. de Boer, and Don F. Westerheijden. Establishing research universities in Ukrainian higher education: the incomplete journey of a structural reform. Journal of Higher Education Policy and Management, 38(2), 2016: 111-125. https://doi.org/10.1080/1360080X.2016.1150232

Hladchenko, Myroslava. The organizational identity of Ukrainian universities as claimed through their mission statements. Tertiary Education and Management, 22(4), 2016: 376-389. https://doi.org/10.1080/13583883.2016.1236144. 
Hladchenko, Myroslava, Dominik Antonowicz, and Harry F. de Boer. Understanding the changes of the higher education governance in Poland and Ukraine: Institutional Analysis. In Deem, R. (ed.). The University as a Critical Institution? Leiden: Brill Sense, 2017: 55-74.

Hladchenko, Myroslava, Don F. Westerheijden, and Harry F. de Boer. Means-ends decoupling at the state level and managerial responses to multiple organisational identities in Ukrainian research universities. Higher Education Research \& Development, 37(4), 2018: 744-757. https://doi.org/10.1080/07294360.2018.1453786

Jongbloed, Ben, Jürgen Enders, and Carlo Salerno. Higher education and its communities: Interconnections, interdependencies and a research agenda. Higher Education, 56(3), 2008: 303-324. https://doi.org/ 10.1007/s10734-008-9128-2

Kezar, Adriann, and Peter D. Eckel. The effect of institutional culture on change strategies in higher education: Universal principles or culturally responsive concepts?. The Journal of Higher Education, 73(4), 2002: 435-460. https://doi.org/10.1080/00221546.2002.1 1777159

Kohler, Jürgen, and Josef Huber. Higher education governance between democratic culture, academic aspirations and market forces (Vol. 5). Strasbourg: Council of Europe Publishing, 2006.

Kuraev, Alex. Soviet higher education: An alternative construct to the western university paradigm. Higher Education, 71(2), 2016: 181-193. https://doi.org/ 10.1007/s10734015-9895-5

Locke, William, William K. Cummings, and Donald Fisher (Eds.). Changing governance and management in higher education: The perspectives of the academy (Vol. 2). Springer Science \& Business Media, 2011.

Magalhães, Antonio, Amelia Veiga, Filipa M. Ribeiro, Sofia Branco Sousa, and Rui A. Santiago. Creating a common grammar for European higher education governance. Higher Education, 65(1), 2013: 95-112. https://doi.org/ 10.1007/s10734-012-9583-7

Oleksiyenko, Anatoly. Socio-economic forces and the rise of the world-class research university in the post-Soviet higher education space: The case of Ukraine. European Journal of Higher Education, 4(3), 2014:249-265. https://doi.org/10.1080/21568235.2014.916537

Oleksiyenko, Anatoly. Higher education reforms and center-periphery dilemmas: Ukrainian universities between neo-Soviet and neo-liberal contestations. In Zajda, Joseph and Val Rust (eds). Globalisation and higher education reforms. Cham: Springer, 2016: 133-148.

Oleksiyenko, Anatoly. Enhancing university staff capacities for critical inquiry: Organizational change, professional development and cumulative powers in higher education. In Postiglione, Gerard A. and Jisun Jung (eds.). The changing academic profession in Hong Kong. Springer, Cham, 2017: 125-142.

Oleksiyenko, Anatoly. Zones of alienation in global higher education: corporate abuse and leadership failures. Tertiary Education and Management, 24(3), 2018: 193-205. https:// doi.org/10.1080/13583883.2018.1439095

Oleksiyenko, Anatoly, Quiang Zha, Igor Chirikov, and Jun Li (eds.). International status anxiety and higher education: The Soviet legacy in China and Russia. Hong Kong: CERC/Springer, 2018.

Oleksiyenko, Anatoly, and Nian Ruan. Intellectual leadership and academic communities: Issues for discussion and research. Higher Education Quarterly, 2019. https://doi. org/10.1111/hequ.12199 
Padure, Policy Lucia, and Glen A. Jones. Policy networks and research on higher education governance and policy. In Huisman, Jeroen (ed.). International Perspectives on the Governance of Higher Education. Routledge, 2009: 133-152.

Paradeise, Chatrine, Emanuela Reale, Ivar Bleiklie, and Ewan Ferlie (Eds.). University governance. Dordrecht: Springer, 2009.

Rowlands, Julie. Academic boards: less intellectual and more academic capital in higher education governance? Studies in Higher Education, 38(9), 2013: 1274-1289. https:// doi.org/10.1080/03075079.2011.619655

Sagintayeva, Aida, and Kairat Kurakbayev, K. Understanding the transition of public universities to institutional autonomy in Kazakhstan. European Journal of Higher Education, 5(2), 2015: 197-210. https://doi.org/ 10.1080/21568235.2014.967794

Stensaker, Bjorn, and Agnete Vabø. Re-inventing shared governance: Implications for organisational culture and institutional leadership. Higher Education Quarterly, 67(3), 213: 256-274. https://doi.org/ 10.1111/hequ.1 2019

Svyrydenko, Denys. Divided universities: the postcolonial experience of contemporary Ukrainian higher education. Future Human Image, 1(7), 2017: 128-135.

Tierney, William G. Higher education research, policy, and the challenges of reform. Studies in Higher Education, 39(8), 2014: 1417-1427. https://doi.org/10.1080/03075079.20 14.949534

Vidovich, Lesley, and Jan Currie. Governance and trust in higher education. Studies in Higher Education, 36(1), 2011: 43-56. https://doi.org/10.1080/03075070903469580

Vukasović, Martina, and Mari Elken. Higher education policy dynamics in a multi-level governance context: A comparative study of four post-communist countries. In Zgaga, P., Teichler, U., and Brennan, J. (eds.). The globalisation challenge for European higher education. Convergence and diversity, centres and peripheries.. Frankfurt am Main: Peter Lang Verlag, 2013: 261-286. 